\title{
Associative Interference and Premorbid Adjustment in Schizophrenia
}

Clifford Leo Hirsch

Loyola University Chicago

Follow this and additional works at: https://ecommons.luc.edu/luc_diss

Part of the Psychology Commons

\section{Recommended Citation}

Hirsch, Clifford Leo, "Associative Interference and Premorbid Adjustment in Schizophrenia" (1971). Dissertations. 1189.

https://ecommons.luc.edu/luc_diss/1189

This Dissertation is brought to you for free and open access by the Theses and Dissertations at Loyola eCommons. It has been accepted for inclusion in Dissertations by an authorized administrator of Loyola eCommons. For more information, please contact ecommons@luc.edu. (c) $($ ) $\Theta \Theta$

This work is licensed under a Creative Commons Attribution-Noncommercial-No Derivative Works 3.0 License. Copyright @ 1971 Clifford Leo Hirsch 


\section{ASSOOIATIVE INTERFERENOE AND PREMORBID \\ ADJUSTMENT IN SCHIZOPHRENIA}

Clifford Hirsch

-

A Dissertation Submitted to the Faculty of the

Graduate School of Loyola Untversity in

Partlal Fulfillment of the Re-

quirements for the Degree

of Doctor of Philosophy

Chicago, Illinols

May, 1971 


\section{Acknowledgments}

I am deeply grateful to the members of my advisory committee, Dr. Robert Solso, Director, Dr. Alan DeWolfe, Dr. John Shack, and Dr. Ronald Walker who gave generously of their time, knowledge, and experience in the supervision of this study. Special thanks is due Dr. Alan DeWolfe who not only shared his knowledge of schizophrenic behavior, but whose day to day contact with the profect was a source of continual encouragement.

I am also indebted to Dr. Albert Erlebacker for his consultation on the statistical analysis and to Mr. Joseph Konieczny who was an invaluable assistant in the preparation of the equipment and in the collection of the data for this project. Thanks are also expressed to Mr. Robert Gustafson for his help in obtaining, classifying and matching the patient subjects used in this study.

Gratitude is expressed to the Veterans Administration Hospital, Downey, Illinols for the facilities and resources which were provided for this project. Special thanks are extended to the subjects of this study, the patients and the volunteer hospital staff, without whose generous cooperation this investigation would not have been possible.

Finally, I wish to express my gratitude to my wife, Mary, who spent many hours typing rough drafts and the final 
copy of this dissertation while also admirably meeting her. more usual duties as wife and mother. To her, too, goes my deepest love, for her emotional support of this project, as of all my graduate education, has been abundantly present throughout. 


\section{Life}

Olifford Leo Hirsch was born in Milwaukee, Wisconsin, May 27, 1942. He was graduated from Wash1ngton H1gh School In Milwaukee, January, 1961. He began his undergraduate studies at Marquette University, M1lwaukee, and obtalned a Bachelor of Sclence degree in June, 1965.

He began graduate studies at Marquette University in September, 1965, and recelved the degree of Master of Science in June, 1968.

He began doctoral study at Loyola University in September, 1968. He held a Veterans Administration traineeship from July, 1968, to July, 1971. He has been a Lecturer in the Department of Psychology at Loyola University in 1969, 1970, and 1971. 


\section{Table of Contents}

Chapter 1 - Introduction .................... 1

Associative Interference in Schizophrenia ..... 1

The Process-Reactive Distinction ........... 11

Verbal Learning Methodology .............. 13

Chapter 2 - The Problem ....................... 19

Chapter 3 - Method ........................ 21

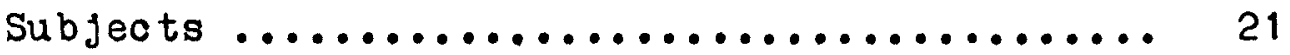

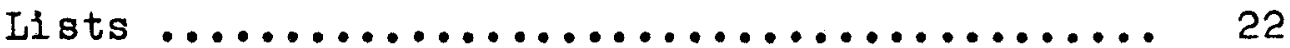

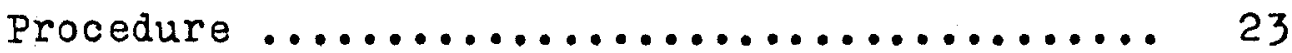

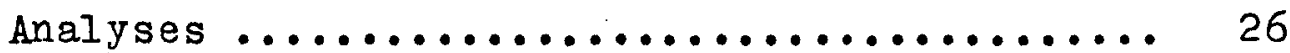

Chapter 4 - Results ........................ 30

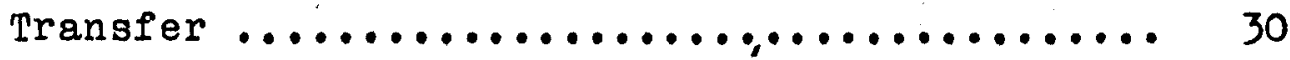

MMFR ................................ 33

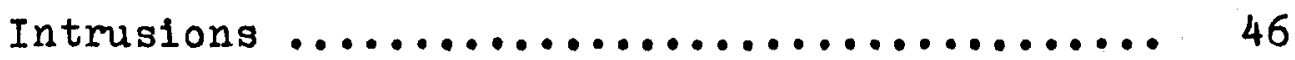

Chapter 5 - Discussion ..................... 50

Chapter 6 - Summary ........................ 65

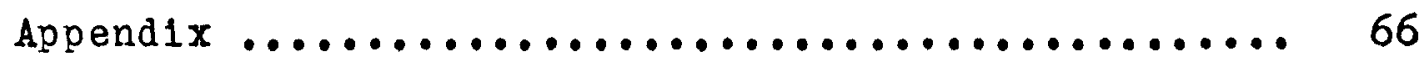

References .............................. 67 
Introduction

Assoclative Interference in Schizophrenla

Bleuler (1950) appears to have been one of the first to focus on associational disturbance as an explanation of the psychological deficit found in schizophrenia. Mednick (1958) elaborated on this concept and delineated the relat1onsh1p between arousal level and associative disruption in schizophrenia. He anchored his thinking in the Hullian notion of generalized drive (D) which in Hull's system is the central motivational force (Hull, 1943). According to Hull a multiplicative relationship holds between response strength and drive. Increasing drive (D) raises the strength of all responses in the organism's response repertory because this type of general arousal is without direction. Mednick reasoned that in individuals with high drive levels learning of simple tasks (those with few competing responses) should proceed at a rapld rate. However, in complex tasks, learning should be impeded by response competition.

Mednlck assumed that schizophrenics are individuals with very high drive levels, especially during the acute phase of their disorder. Although he did not elaborate on the etiology of helghtened arousal, he felt that individuals in such a state effect an adjustment to the environment 
which reduces stimulation (1.e, soolal and emotional withdrawal) and keeps drive within acceptable limits. However, some traumatic event interferes with this adjustment raising the drive level. With increased drive, stimulus and response generalization increase. The Individual then becomes caught in what Mednick termed the "reciprocal augmentation of anxiety and stimulus generalization (p. 322)." A vicious circle of increasing drive with attendant stimulus generalization and more drive elevating stimuli brought above threshold evoke arousal responses. Each increase in generalization and number of suprathreshold stimuli is followed by another increment in drive, and the cycle continues repeatedly until the individual reaches some physiological limit. At this point, thought sequences are disrupted. Any stimulus-thought elicits usually remote associates which have become suprathreshold as the result of the drive increment. Thought disorder is evidenced in 1rrational relationships between cognitive elements, in clang association, and at its height, in word salad (1.e., the loss of appropriate grammatical connections and order in the verbalizations).

Mednick described the transition from this state to chronicity. Certain remote associates bring about a drive. decrement, because they are not so closely problem orlented. The drive decrement is reinforcing, and soon much of the schizophrenic's thought may be occupied with these initially tangential associations. In the chronic phase of the disorder, drive decrement may continue until the individual 
18. 4ndef-2ro:2391:

Several aspects of Mednick's thoory dre somewhat confusing (Epstein and Ooleman, 1970). Mednick's use of the Hullian concept of drive was often equivocal. Drive is an intervening variable anchored in need deprivation and stimulus intensity and expressed in responses which are subject to measures of performance. However, Mednick often equated it to anxiety which is an avoldance motive. He further assumed that drive or anxlety can be measured directly by indexes of physiological arousal.

He, thus, confused generalized arousal with specific arousal with a definite directional component. His idea that physiological measures provide techniques for assaying anxiety further attests his confusion of the concepts and the nature of their inter-relation. Today of course, the lack of agreement between the various physiological measures in varlous systems under different conditions is recognized.

Mednick's use of the threshold concept also seems to be questionable. Only at that point where the dominant response is barely suprathreshold and the competing response is barely subthreshold should response competition in high-drive individuals be a special problem. Once both responses are suprathreshold, increasing drive should increase the probability of the dominant response belng el1cited. A concept such as response celling would appear to be more efficacious in the suprathreshold situation (Broen 
and Storms, 1966; Storms and Broen, 1969).

Desplte the difficulties c1ted, Mednlok's theory pro-

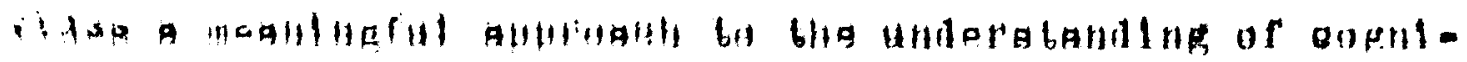

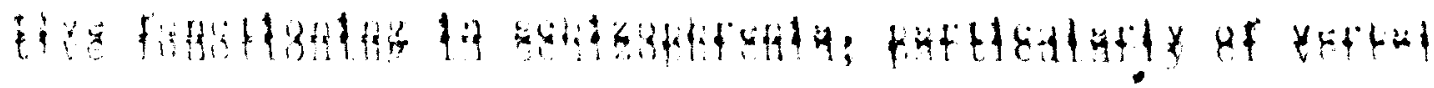
learning phenomena, and is deserving of further empirical testing.

The hypotheses generated from the theory are open to direct experimental verification, and point the way to 1mportant experiments on the relationship of drive level to performance in schizophrenics and normals, and on response interference in simple and complex tasks. No matter what the outcome of such research, it should provide information of some importance

(Epstein and Coleman, 1970, p. 115).

A series of studies have appeared in the research 11 terature using verbal learning paradigms to investigate these relationships. Verbal learning tasks with little to no assoclative interference have been used as simple tasks, and those high in associative interference have been used as complex tasks.

Mednick and deVito (in Mednick, 1958) did not find evidence that schizophrenics learn faster than normals on low interference lists but did find their performance to be inferior to normals in the high response competition condition.

Carson (1958) 1nvest1gated normals, schizophrenics, and organics using a verbal learning task. He used three experimental serial lists which differed in amount of intra-list similarity based on extra-experimental criteria. He found normals to be most affected by Increased 
associative interference w1th organics and schizophrenics being relatively unaffected. There was no slgnificant difference between the neuropsychiatric groups.

Another study (Donahoe, Curtin, and Lipton, 1961) tested the hypothesis using serial Iists. Interference was manlpulated by the interpolation of similar or dissimilar material between the acquisition of a I1st and 1ts relearning. The results indicated that schizophrenics and normals were equally and negatively affected by the interpolation of similar as compared to dissimilar material.

Spence and Lair (1954) used a paired-associates learning task to test Mednick's hypothesis. The exper1mental list in this study was composed of meaningful word pairs of low assoclative strength. However, a response word of high assoclative value for the stimulus word appeared in the list as the response term in another word pair. Thus, there was low association within word pairs but high association across pairs. The results of this study Indicated that both schizophrenics and normals were adversely affected by this type of interference.

However, there was a trend in the data (nonslgnificant) 1ndicating that while sohizophrenio Ss performed moro poorly than normal $\underline{S} s$ on a no-1nterference control 11st, they performed better than normal Ss on the experimental 11st. This trend is opposite to what would be predicted by Mednick's hypothesis and suggests that the extra-experimental manipulation of interference (1.e., based on college 
student word association norms) used in this study was not as effective for schizophrenios as it might have been.

The results of this study were further confounded by several $\underline{S}$ variables. The use of nonpsychiatmc hospitalized Individuals as control Ss is open to question. Olinical experience suggests that such patients are susceptible to personality dismutions, sometimes of psychotic proportions, not only in the acute stage of their 1llness but also at varlous phases of convalescence (the status of the Ss in this study). This impression is strengthened by research results showing that status as a VA hospital patient (nonpsychlatric) makes individuals as susceptible to the disruptive effects of censure as are schizophrenics (Gladis and W1 schner, 1962).

The actual chronicity of the schizophrenic Ss in the Spence and Lair study is also of some concern. Although current hospitalization was limited to 12 months, there was no control for number of previous admissions.

An Important methodological advance in the study of assoclative interference in schlzophrenia occurred with an Investigation by Kausler, Lair, and Matsumoto (1964). They manipulated interference experimentally rather than by extra-experimental word-association norms as earlier studies had done. A mixed 11st with three transfer paradigms ( $A-C$, $A-B r$, and $C-D$ ) was used (Twedt and Underwood, 1959). This technique assured that both normal and schizophrenic $\underline{S}$ were being subjected to interference. 
The results of the study indloated that sohizophrenio Ss made signiflcantly more errors in the highest interference paradigm (A-Br) than did normal Ss. Thls result was independent of a signiflcant main effect of groups in both Iist 1 and Iist 2 showing the schizophrenic Ss to be inferlor in learning ability across 11 sts and across paradigms. The latter finding was probably a function of the sample used in this study and is not representative of schizophrenic individuals in general.

Several factors confound the results of Kausler, et a1. First, fewer schizophrenic than normal Ss reached the criterion of one perfect trial on List 1; therefore, the pre-measurement strength of S-R associations probably differed between groups. An attempt was made to check the possible effects of this inequity by dolng a separate analysis using only those Ss from each group who reached the criterion of one perfect trial on Llst 1. The results of this analysis paralleled those of the main analysis. However, the dependent variable in the latter analysis was a questionable difference score (A-Br absolute transfer score minus A-C absolute transfer score). This particular manipulation appears to have been based on the assumption that $A-B r$ and $A-C$ are only quantitatively different interference paradigms. Recent evidence, however, indicates that they are also qualitatively quite different. A-O Interference results from failure to Inhibit I1st 1 response terms while A-Br interference results not only from response competition 
but also from disruption of speciflc associations (Barnes and Underwood, 1959; Postman and Stark, 1969).

Second, the use of all chronic (lengthy hospitalization) schizophrenic Ss (there is no indication of how they were selected) confounds the interpretation of the results with institutionalization.- Finally, the use of a 4:4-second exposure rate with a 10 second intertrial interval, al though intended to facilitate learning in the schizophrenic S may have actually been detrimental to their performance. Schizophrenic Ss often show difficulty in maintaining attention to external stimulation.

Schooler and Tecce (1967) used a mixed list with palred-assoclates varying in associative strength and intra-list response competition. Association values were established extra-experimentally. They tested partially remltted schizophrentcs, regressed schlzophrentcs, and normals under conditions of positive evaluation, negative evaluation, and no evaluation. The results of this study appear to be basically uninterpretable because the measure used (change scores reflecting differences in performance from List 1 to IIst 2) so confounds the normat1ve manipulation within each list with the interaction of 11 sts that the effects cannot be differentlated.

Another study (Kapche, 1969) falled to support the interference hypothesis. However, mantpulation of interference, again, was based on extra-experimental criteria. Normal and schizophrenic $\underline{S}$ took more trials to learn a 
paired-associates $11 \mathrm{st}$ and gave fewer correct responses as interference increased. However, there was a trend in the data indicating that overt errors of all types increased

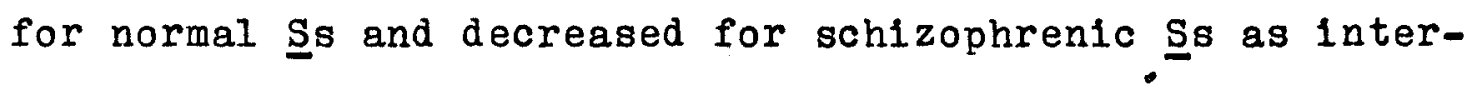
ference increased. This trend, like that noted in the Spence and Lair study, was in the opposite direction to that predicted by Mednlck's theory. Once again, differential effectiveness of college student norms for the manipulation of interference in the two $\underline{S}$ groups appears to be $a$ plausible explanation.

Streiner (1959) used a Indtiple cholce peired-

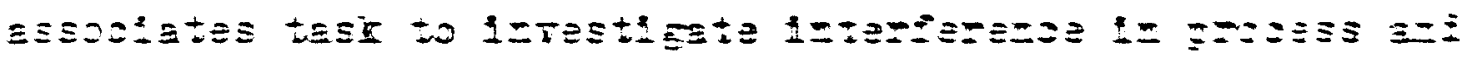
reactive schizophrenics and normals. Interference was mantpulated by extra-experimental norms. He found that performance decreased across groups wt th increasing interference. The most salient difficulty in this investigation was the confounding of the findings by a reduction in exposure time from the low complexity task ( 15 seconds) to the high complexity task ( 8 seconds) which may have masked interference effects.

Another study attempted to replicate the Spence and Lair findings (Gonen, 1970). Schizophrenic Ss in this Investigation were differentiated according to premorbid adjustment and paranold-nonparanold status. All sch1zophrenic Ss showed performance deficit on the second list, but the above $\underline{S}$ variable classifications were not signif1cant nor did they interact with treatment. No normal 
control group was used so the comparative evidence required to evaluate Mednick's hypothesis 1s lacking.

It is clear that the results of the above studies generally do not support an interference theory explanation of schizophrenic deficit. However, all of these studies except those of Donahoe, et al. (which ylelded negative evidexce) and Jausler, et al. (which ylelded supportis orldence) suffer from the methodological flaw of nonexporlinental manipulation of interference. It seems incongruous, and the Spence and LaIr, and Kapche studies offer suggest1ve supporting evidence as noted, to test hypotheses about assoclative interference in schizophrenia using material in which the amount of interference is varied according to extra-experimental standards developed on normals. Schizophrenics, it should be recalled, are thought to suffer from disturbance of the typical pattern of association.

Furthermore, the results of those studies using high response term similarity in the second list could be predicted given the assumption about schizophrenia upon which they are based. Analysis of paired-associates learning into two functional stages (Underwood, Runquist, and Schulz, 1959; Underwood and Schulz, 1960) suggests that the high-drive schizophrenic Ss might integrate second list response terms more quickly than would normal S.s. However, their highdrive would cause them to make more errors in the associative or "hookup" stage. The net effect, then, is likely to be a performance defic1t for both groups on the second 11st, 
but no difference between the groups. The latter effect would be an artifact of the differential performaneas of each group in the two stages which would tend to canoel each other out across entire I1st 2 learning (Goulet, 1968). Finally, all of the above studies, except that of Spence and Lair, suffer from a confounding of possible interference effects, pathology, and institutionalization. The use of chronic schizophrenic Ss in these studies does not allow the differentiation of effects attributable to the actual schizophrenic process and those which are response acretions resulting from severe and artificial circumstance (1.e., institutionalization).

The current study will attempt to Improve the design to obviate the above difficulties. Interference w1ll be manipulated experimentally and chronicity w1ll be controlled. Further, an attempt will be made to refine the interference concept of schizophrenic deficit by dichotomizing schlzophrenla into process and reactive types.

The Process - Reactive Distinction

The process-reactive distinction in schlzophrenia, as the assoclative disturbance concept, dates from Bleuler who recognized that al though some schizophrenics never recover, others do. Those who do not recover, process schizophren1cs, sometimes were thought to be genetically tainted and by definition to have a poor premorbid history with an insidious onset of psychosis. Those with a better prognosis, reactive schizophrenics, are often thought to be free of 
genetic taint (psychogenio in otiology) and by definition to have a good premorbid 11 fe h1story w1 th a adden onset of psychosis. Phillips (1953) developed a scale to distinguish the groups.

Several reviews (Herron, 1962; H1ggins, 1964, 1969; H1ggins and Peterson, 1966) Indicate that the processreactive distinction is a viable concept with an evergrowlng literature. Higgins (1969) did not report any work relating interference theory and the process-reactive dimension. Work in associative processes in this area has been concerned with associative commonality.

Several relevant studies have appeared in the 11 terature since the Higgins review. Jongsma, Sullivan, and Martin (1969) falled to find differences between process and reactive schizophrenic Ss and normal Ss in complex task conditionability. The task was learning the order of 1llumination of a series of lights. Their sample was small, and the

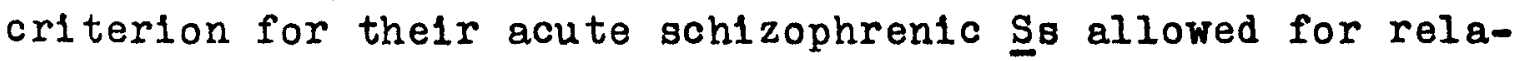
tively long periods of hospltalization (1.e., up to three years).

Irwin and Renner (1969) used simple and complex memory tasks to investigate process-reactive differences in learning under conditions of praise, censure, and nonevaluation. Their results are not supportive of an interference conceptualization, but it should be noted that the results are confounded with length of hospitalization. Also the complexity of the experimental tasks was such as to 
becloud what factor or factors might have been operative in effecting the results.

The two studies c1ted earlier (Gonen, 1970; Strelner, 1969) which used verbal learning methodology to investigate associative interference and premorbid adjustment in schizophrenia are directly relevant. As noted both produced negative results but were open to the criticisms associated with uncontrolled length of hospltalization and the use of nonexperimental means of interference manipulation.

Al though the process-reactive distinction in schizophrenia has produced significant classificatory refinement and consequent increases in understandable variance in this psychopathological group with respect to many dependent variables, this has not so far been the case in associative interference. However, that the number of studies is small and their results questionable is evident.

Verbal Learning Methodology

In addition to the methodological improvements of experimental manipulation of associative interference and of dichotomizing the schizophrenic Ss along the processreactive continuum, the present study will further control interference by using an overlearning technique (Postman, 1962a). This approach plus the adfunct of collecting modifled, modified free recall (MMFR) data 1 s not only concerned with interference but also with the "fate" of the first-list assoclations in the various transfer paradigms (Barnes and Underwood, 1959). Analysis of Intrusions may provide 
additional relevant information.

Barnes and Underwood (1959), using a normal population, concluded that first-11st associations are ext1nguished in the A-B, A-C (old stimulus-new response) paradigm. Postman (1962b), again using a normal population, but with a mixed list approach obtalned results which are highly comparable with those of Barnes and Underwood using homogeneous 11sts. Other studies have consistently confirmed the inhibition or extinction of first list response terms in the A-C paradigm (Delprato and Garskof, 1969; Postman, 1962a; Postman and Stark, 1969; Solso, 1969).

In the $A-B, A-B r$ (old stimulus-response from original list but previously paired with another stimulus) paradigm, several studies have found a high correlation between losses in List 1 MMFR and negative transfer (Postman, 1962a; Solso, 1969). Postman and Stark (1969) used five transfer groups and two conditions of practice (Recall method and Multiplecholce method) to investigate the effect of response avallablitty in trangfer and interference. The paradigms tested were: $C-D, C-B, A-C, A-B r, A-B^{\prime}$. Recall and test trials were alternated under each condition. Ilst 1 recall data was collected at the end of second list learning.

In condition Multiple-cholce, Postman and stark found that $\mathrm{A}-\mathrm{Br}$ was the only paradigm to show appreclable retroactive inhibition (RI). The classical paradigm of unlearning, A-C, showed only 5\% RI. In condition Recall, all paradigms showed considerable RI; it was greatest for A-C, 
followed in order by $A-B r, A-B^{\prime}, O-B$, and $O-D$, 41 paradigms showed greater RI in condition Recall than in cond1tion Multiple-cholce. This difference was greatest for A-O and smallest for $O-B$ with A-Br falling between. The investigators concluded,

In general, the increases are greater (a) when the responses in the two ilsts are different than when they are the same, and (b) when the stimuli remain the same than when they change (p. 173).

Further analysis indicated that $\mathrm{A}-\mathrm{Br}$ was the only paradigm showing significantly more RI than a rest group in condition Multiple-choice. In condition Recall, rellable RI was found for the $A-C, A-B r$, and $A-B^{\prime}$ paradigms when compared to an appropriate rest group.

Analysis for interference with specific associations (1.e., where responses may be assumed to be fully avallable but the bond between them disturbed or lost) indicated that $A-B r$ was the only paradigm showing such an effect.

The above findings are 1mportant to the present study in that they confirm that the interference found in the A-C paradigm probably results from response competition, and that successful learning of I1st 2 palrs depends on the inhibition of List 1 response terms. Disruption or extinction of specific associations does not occur in this paradigm. However, in the A-Br paradigm, loss of specific assoclations (true associative interference) does occur in addition to response competition. Thus, although $A-C$ and $A-B r$ are roughly "interference paradigms," there appears to be a difference in the nature of their mechanisms. 
What, then, are the effects of overlearning or overtraining on List 1 for paradigms $A-O$ and $A-B r ?$. Postman (1962a) investigated the effect of overlearning on several transter paradigms including $\mathrm{A}-\mathrm{C}$ and $\mathrm{A}-\mathrm{Br}$. He used meaningful words. His data reflected a decrease in A-O negative transfer (as measured by mean number of correct responses In the first 10 trials of List 2) with increased first list practice. The A-Br paradigm, however, showed steadily increasing negative transfer with overlearning. The Iist 1 MMFR data also reflected these differences. In the low overlearning condition A-Br responses were recalled better than A-C responses, but with increasing number of List 1 reinforcements the paradigms switched positions so that in the high overlearning condition A-C responses were recalled better than $\mathrm{A}-\mathrm{Br}$ responses.

Solso (1969) used high and low meaningful trigrams (CVOs) to investigate the effeots of manolvo overlparlllll: $(100$ ) on $A-C, A-B r$, and $O-D$ transfor paradlgma fll a wl xod 11st. He found reduced negative transfer in the A-Br paradigm with overlearning. This is contradictory to Postman's finding with meaningful words and Jung's (1962) earlier finding with CVCs.

A series of studies by James and Greeno (1970) confirmed the Postman and the Jung findings with adjectives except where the 11st was relatively short (s1x pairs). With short lists or with digits (usually considered meaningful material) overlearning had no effect. 
The majority of the studies deallng with the effects of overlearning on transfer of training support the hypothesis that with meaningful words and normal Ss overlearning increases interference in the $\mathrm{A}-\mathrm{Br}$ paradigm. Furthermore, overlearning may decrease the amount of interference in the A-C paradigm, al though it did not result in positive transfer in any of the studies reviewed here. This has occured In some studies (see Mandler, 1962). Finally, Postman's study suggests that complementary findings will appear in Iist 1 MMFR data for each paradigm. No one has investigated the effects of overlearning on transfer in a schizophrenic group.

One final methodological issue is of concern. Twedt and Underwood (1959) demonstrated that transfer effects were essentially comparable for mixed and unmixed lists in all of the paradigms they tested (these included those used in the present study: $A-B r, A-O$, and $C-D)$. Since that time some Investigators have found contradictory results. Slamecka (1967) for example found negative transfer for the A-Br paradigm in a mixed list but positive transfer for the same paradigm in an unmixed 11st. The question of the comparability of results employing the different procedures appears to be a methodological problem which has not yet been sat1sfactorily answered. The present study, however, will employ a mixed list design in keeplng with the earlier work of Kausler et al. (1964). This approach seems justiflable in light of the reduction in experimental session length made 
18

possible by such an approach, which is important with schizophrenic Ss, and in light of the major thrust of the study which concerns the performance of a pathological group on a task in which associative interference is present. 


\section{The Problem}

Mednick's theory makes differential predictions about the drive level of acute and chronic schizophrenics. The former are thought to be in a state of over-arousal, and the latter are thought to be under-aroused. The hypothesis that Mednick put forth concerning associative interference in schizophrenia depends on the assumption that high drive results in response competition. However, the verbal learning studies intended to elucidate this phenomenon, with the single exception of Spence and Lair (1964), have used chronic schizophrenic Ss. Furthermore, the use of chronic schizophrenic patients confounds any findings with the extrinsic effects of institutionalization.

It seemed that this undesirable consequence could be avolded by classifying schizophrentcs as process or reactive (a measure of their pre-hospital history of disorder) and by keeplng hospitalization to a minimum. This notion gained further support from the existing literature which suggested (as did clinical experience) that process and reactive schizophrenics might differ in drive level in a manner slmilar to that suggested by Mednick for chronic and acute schizophrenịcs.

Several reviews of the process-reactive 11 terature (Fowles, Watt, Maher, and Grinspoon, 1970; H1ggins, 1969) 
Indicate that studies of arousal using physlologioal

measures have resulted in confused and of ten conflicting findings. The principle emerging from these studies is that there is Iittle direct covariance among physiologic systems and measures. On a behavioral level, however, many studies have found process schlzophrenics to respond with minimal energy and reactives with much energy in a variety of tasks (Crider, Grinspoon, and Maher, 1965; Donoghue, 1964; H1ggins, Mednick, Ph111p, and Thompson, 1966; H1ggins, Mednick, and Thompson, 1966; Relsman, 1960; Reynolds, 1965; Sm1th, 1961; Zlotowsk1 and Bakan, 1963). Only two studies offered nonsupportive results (KIeIn, Cicchette, and Spohn, 1967; Schweld, 1966). W1 th respect to behavioral reactivity, then, good and poor premorbid schizophrenics may be thought to fall at the opposite ends of an inverted-U curve representing the relationship between drive and performance. Both groups might be expected to perform more poorly than normals but for different reasons; poor premorbids because of too little arousal or drive and good premorbids because of too much reactivity. Task complexity (1.e., degree of associative interference) would be expected to interact with reactivity to affect performance.

At a behavioral level, the following prediction was made: That the performance of reactive schizophrenics would be more negatively affected by increased associative interference in a task than would the performance of process schizophrenics or normals. 
Method

Subjects

The Ss were 60 hospitalized, male schizophrenic patients and 30 male hospltal employees. The schizophrenic Ss were obtalned through the Central Testing Service of a large VA Hospital in which all first and second admissions are routinely examined. They were classifled as either good or poor premorbld schizophrenta using a questionnaire self-report scored on a revision of the phillips scale of Premorbid Ad Justment in Schizophrenia (Phillips, 1953; Dewolfe, 1968). Those scoring 12 or below on the scale were considered to be good premorbids and those scoring 18 or above were considered to be poor premorbids. W1thin the limitations imposed by matching Ss were taken consecutively until there were $30 \mathrm{Sg}$ in each category. The diagnosis of schizophrenia was made according to the usual neuropsychiatric criteria. Any patient who had ever carried a diagnosis of organic brain damage, alcohollsm, or drug addiction was excluded. The schizophrentc sample was further restricted by using only acute patients, 1.e., those w1th less than one year current hospltalization.

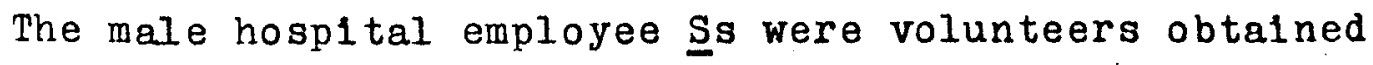
through various hospltal departments, 1.e., Supply, Eng1neering, Nursing, etc. These normal Ss were given a 
non-psychiatric equivalent of the Phillips gcale, and only those scoring 12 or below (1.e., "good premorbid") were used in the study.

\section{Ilsts}

A mixed list paired-assoclates learning task (Twedt and Underwood, 1959) was used. Three transfer paradigms were represented: $A-B, A-C$ (old stimulus-new response) $A-B, A-B r$ (old stimulus-response from original list but previously paired with another stimulus), and $A-B, C-D$ (new st1mulus and new response). L1sts 1 and 2 each contalned six pairs of words from the Russell and Jenkins (1954) revision of the Kent Rosanoff Word Association Test. No stimulus or response word was an assoclate of any other word with a frequency greater than 1/1008. All words comprising the list were roughly equated for meaningfulness as indicated by familiarity using the Lorge-Thorndike (1944) word count. The words had a frequency of appearance greater than 37 per mililon. All words began with a different letter and were screened for formal simllarities (1.e., rhymes, or logical categories). Thirteen of the elghteen words were nouns and the rest were adjectives. Pairs were estabIIshed using a random procedure with the exception that no ad jective appeared as a stimulus..

List 2 contalned two pairs for each of the three paradigms and was 1dentical for all Ss. Ilst 1 was used with three varlations allowing each word pair to be employed in each of the three paradigms as described by Twedt and 
Underwood (1959) and Kausler and Kanot1 (1963). Thus confounding of paradigmatic effects with speciflc properties of the word pairs (e.g., differential acquisition rates) was controlled. Four different random arrangements of each List 1 paradigmatic variation and of List 2 were employed to eliminate possible serlal order effects. The experimental I1sts appear in the Appendix.

procedure

Each S was given a practice list (PL) of three word palrs which were presented with modified paired-associates learning instructions. This list (w1th four serial order varlations) was learned by the anticlpation method to a criterion of 15 trials or 1 perfect recitation, whichever occurred first. List 1 was learned to a criterion of one perfect recitation. Half of the $\underline{S}$ in each group were then glven additional trials to a criterion of $50 \%$ overlearning. The schlzophrenic $\underline{\text { S }}$ classifled according to premorbid adjustment and overlearning (OI) or no overlearning (N) were matched for inftial learning rate as indicated by the number of trials involved in learning list 1 to a criterion of one perfect recitation. Al though the normal Ss were not matched to the schizophrenic Ss for inltial learning rate, they were not found to be slgniflcantly different from the pathological groups with respect to flrst list acquisition. Relevant means and standard deviations appear in Table 1. The analysis of varlance appears in Table 2. There were no significant differences between the $\underline{S}$ groups in age or 
24

Table 1

Means and Standard Deviations

for Schizophrenic LIst 1 Acquisition

Classified for 2 Degrees of Learning

(OI=overlearning, $N=$ no overlearning)

\begin{tabular}{lcr}
\multicolumn{1}{c}{ Group* } & $\begin{array}{c}\text { Number of Trials to Criterion } \\
\text { Mean }\end{array}$ & S.D. \\
& 15.67 & 8.09 \\
Process-OI & 16.27 & 10.87 \\
Reactive-OI & 11.20 & 7.19 \\
Normal-OI & 14.07 & 8.78 \\
Process-N & 13.33 & 6.24 \\
Reactive-N & 12.53 & 6.24 \\
Normal-N & & \\
*N=15 in each Group & &
\end{tabular}




\section{Table 2 \\ Analysis of Varlance \\ for Schtzophrenic and \\ Normal Iist 1 Acquisition}

$\begin{array}{lrccc}\text { Source } & \text { df } & \text { MS } & \text { F } & \text { P } \\ \text { Groups } & 5 & 54.63 & <.00 & \text { NS } \\ \text { Error } & 84 & 69.91 & & \\ \text { Total } & 89 & & & \end{array}$


education. Relevant data and analyses appear in Tables 3 and 4.

A two minute period of informal conversation intervened between the completion of List 1 learning and the beginning of practice on List 2. List 2 learning continued to a criterion of 1 perfect recitation or 10 trials, whichever occured first. A 2:2-second exposure rate and a 4second intertrial interval were employed with all 11sts. Material was presented to the Ss with a 303-C Layfayette Memory Drum. All of the Śs' responses were recorded to allow for an analysis of errors.

Immediately following the completion of List 2 learning, modified, modified free recall (MMFR) data was collected (Barnes and Underwood, 1959; Briggs, 1954; Melton, 1961). The Ss were provided with a list of the stimulus words for this experiment. Each word was followed by the appropriate number of blanks (1.e., one or two). The $\underline{S}$ were asked to fill in the response terms as they came to mind. Two minutes were allowed for this initial recall. The Ss were then asked to designate by writing a 1 or a 2 next to each recalled response the list from which each response came. An additional two minutes were allowed for this.

Analyses

In the main analysis List 2 errors were used as the dependent variable in a $3 \times 2 \times 3$ analysis of variance (groups $x$ degree of orlginal learning $x$ paradigms), where paradigns 
Table 3

Means and Standard Deviations

for Age and Education

\begin{tabular}{lrrrr} 
Group* & \multicolumn{2}{c}{ Age } & \multicolumn{2}{c}{ Education } \\
& Mean & S.D. & Mean & S.D. \\
& & & & \\
Process & 37.27 & 9.94 & 11.93 & 2.13 \\
Reactive & 35.50 & 10.80 & 12.27 & 2.09 \\
Normal & 37.00 & 10.24 & 12.87 & 2.29 \\
& & & & \\
*N=30 in each Group & & &
\end{tabular}


28

Table 4

Analyses of Variance

for Age and Education

$\begin{array}{lrrcc}\text { Source } & \text { def } & \text { MS } & \text { F } & \text { P } \\ \text { Age } & 2 & 27.21 & <.00 & \text { NS } \\ \text { Error } & 87 & 110.52 & & \\ \text { Total } & 89 & & & \\ \text { Education } & 2 & 6.71 & 1.28 & \text { NS } \\ \text { Error } & 87 & 5.26 & & \\ \text { Total } & 89 & & & \end{array}$


$\therefore$ H. He difterence score represents loss of specific njoslations.

Finally, specific List 1 response intrusions into $::$ : A-C paradigm were analyzed in a $3 \times 2$ analysis of varlance (rours $x$ defree or orlagnai learuing). 


\section{Results}

Transfer

Analysis of variance on IIst 2 errors showed significant main effects of interference ( $A-B r$ paradigm plus A-O paradigm vs. C-D paradigm) and type of interference ( $A-B r$ paradigm vs. A-C paradigm). The $\mathrm{p}$ values were $\mathrm{p}<.01$ in both cases. These findings indicate that the experimental manipulation of associative interference was successful when viewed across groups. As expected more errors occured in the $\mathrm{A}-\mathrm{Br}$ paradigm than in the $\mathrm{A}-\mathrm{C}$ paradigm. The $\mathrm{C}-\mathrm{D}$ paradigm showed the smallest number of errors.

A main effect of pathology was also found $(\underline{p}<.05)$. Thus, as a group the schizophrenic Ss made more errors on Ilst 2 than did the normal Ss. A significant interaction ( $\mathrm{p}<.05)$ was found between type of interference (A-C parad $1 \mathrm{gm}$ or $\mathrm{A}-\mathrm{Br}$ paradigm) and type of schlzophrenia (process or reactive). Process schizophrenic Ss made an equal number of errors in both paradigms, while reactive Ss made fewer errors in the A-C paradigm than in A-Br. The reactives' performance, thus, paralleled that of the normal $\underline{S}$. The means and standard deviations for the above results appear in Table 5. The analys1s of varlance appears in Table 6. There were no signiflcant differences between the groups in the control paradigm (C-D). Therefore, a separate 
Table 6

Analys1a of Varlanoe of I1 2 Errors

Source

Pathology (P)

Type of Schizophrenia (TS) -

Degree of Original Learning (DOL)

DOL $\times \mathrm{P}$

DOI $\times$ TS

SS/Groups

Interference (I)

I $\times \mathrm{P}$

I $\times$ TS

I $\mathrm{x}$ DOL

I $\mathrm{x}$ DOI $\mathrm{x} \mathrm{P}$

I $x$ DOI $x$ TS

I $x$ SS/Groups

Type of Interference (TI)

TI $\times \mathrm{P}$

TI $x$ TS

II $X$ DOL

II $\times$ DOL $\times \mathrm{P}$

TI $x$ DOI $x$ TS

TI $x$ SS/Groups

Total df

MS

F

$\mathbf{P}$

1

274.49

$5.51<05$

1

2.00

$<1.00$

NS

38.53

$<1.00$

NS

$16.02<1.00$ NS

92.45

1.86

NS 84

49.78

$716.45 \quad 52.03<01$ $42.40 \quad 3.08 \quad$ NS $18.05 \quad 1.31 \quad$ NS $0.27<1.00 \quad$ NS $0.83<.00 \quad$ NS $10.41<1.00 \quad$ NS 84 13.77 $112.02 \quad 14.64<01$ $5.39<1.00$ NS $32.03 \quad 4.19<05$ $8.89 \quad 1.16 \quad$ NS $2.17<1.00 \quad$ NS $\begin{array}{lll}14.71 & 1.92 \quad \text { NS }\end{array}$ $84 \quad 7.65$ 
analygis using absolute transfer scores (O-D errors minus experimental paradigm errorg) was deemed unneoesary sinoe the results would parallel the raw score analysis. The graphical presentation of List 2 error data in terms of absolute transfer, however, follows convention and is presented in Figure 1.

$\underline{\text { MMFR }}$

Analysis of variance on I1st 1 recall scored under lenient criteria (1.e., response recall was scored irrespective of proper list membership designation) revealed main effects of both interference $(\mathrm{p}<.01)$ and type of interference $(p<.01)$. Once again, the experimental manipulation of interference was successful. All paradigms were found to be significantly different from each other, and the differences were in the expected directions. Recall was best in the control paradigm $(O-D)$, less in the $A-B r$ paradigm and worst in the A-C paradigm.

A significant interaction of interference and type of schlzophrenia was found $(\mathrm{p}<05)$. Process schizophrenio Ss recalled Iist 1 responses in the interference paradigms (A-Br plus A-C) better than did reactive schizophrenic Ss. The schizophrenlc groups, however, did not differ greatly In recall in the control paradigm.

Finally, a significant triple interaction (type of interference $x$ degree of original learning $x$ type of schizophrenia) was found $(\underline{p}<.05)$. In the overlearning condition process schizophrenic Ss recalled List 1 pesponses In the 
34

Figure 1

Amount of Negative Transfer In Mean Number of Errors on List 2

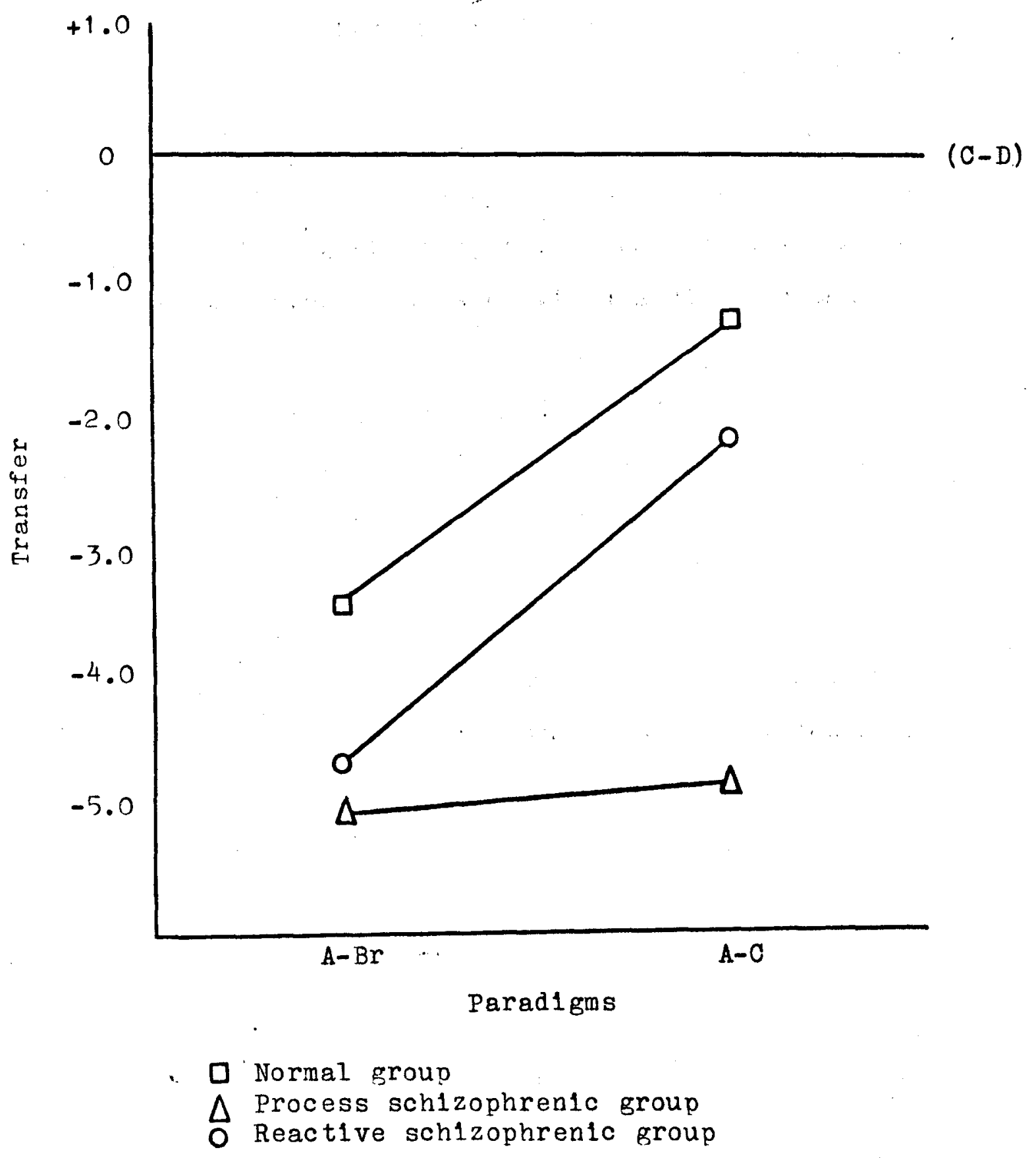


A-Br paradigm to a greater extent than did reactive $\underline{S} 3$, and this difference was signiflcantly greater than that found in the A-C paradigm. Without overlearning, process Ss recalled more List 1 responses in the A-C paradigm than did reactive Ss; no difference between the groups was found in the A-Br paradigm. The above data are presented in Table 7. The analysis of variance is presented in Table 8, and a graphical presentation of the data appears in Figure 2.

List 1 MMFR data were also scored using strict criteria (1.e., requiring correct list membership degignation in addition to correct recall). Subtraction of strict scores from lenlent scores provided a difference score which was an indicator of loss of specific associations. Others (e.g., Postman and Stark, 1969) have used mean differences between lenient and strict scoring to compare groups for such losses. Analysis of variance on these difference scores revealed a main effect of type of interference $(\mathrm{p}<.01)$. All other terms in this analysis were nonsignificant. These findings reflect losses of speciflo associations, across groups, in the A-Br and C-D paradigms which are signiflcantly greater than losges in the A-C paradigm. The data and analysis appear in Tables 9 and 10. Analysis of variance was also carried out on List 2 MMFR data (presented in Tables 11 and 12) with lenient scoring criteria. The main effects of interference and of type of Interference were found to be significant ( $\mathrm{p}<.01$ and $n<05$, respectively). Thus, the differences between parad1gms were slgniflcant; recall in paradigm $C-D$ was 


\section{Table 7}

Means and Standard Deviations

for I1st 1 MMFR (lenient scoring)

Classifled for 2 Degrees of Original Learning

(OL=overlearning, $N=$ no overlearning)

Group*

$$
\mathrm{A}-\mathrm{Br}
$$

Mean S.D.

Process-OL

Reactive-oI

Normal-OI

Process-N

React1ve-N

Normal-N

${ }^{N}=15$ in each Group
Paradi gm

$$
\text { A-C }
$$

$C-D$
Mean S.D.

$1.40 \quad 0.62$

$1.80 \quad 0.40$

1.660 .62

$1.20 \quad 0.81$

1.140 .71

1.460 .63
0.460 .62

1.060 .78
1.46 
Table 8

Analysis of Variance of

L1st 1 MUgR (Ionlent sooring)

Source

de

MS . $T$

$\mathbf{P}$

Pathology (P)

1.90

2.29

NS

Type of Schizophrenia (TS)

$0.80<1.00 \quad$ NS

Degree of Original Learning (DOL) 1

$2.69 \quad 3.24 \quad$ NS

DOL $\times \mathrm{P}$

$\begin{array}{lll}1.67 & 2.01 \quad \text { NS }\end{array}$

DOL $x$ TS

$0.20<1.00 \quad$ NS

SS/Groups

84

0.83

Interference

(I)

$\begin{array}{lll}7.83 & 20.83<01\end{array}$

I $\times \mathrm{P}$

$0.01<1.00 \quad$ NS

I $x$ TS

2.01

5.15

$<05$

I $x$ DOL

0.81

2.08

NS

I $\mathrm{x}$ DOI $\times \mathrm{P}$

0.07

$<1.00$

NS

I $\times$ DOL $\times$ TS

0.65

1.67

NS

I $\times \mathrm{SS} /$ Groups

84

0.39

Type of Interference (TI).

2.94

9.80

«

TI $\times \mathrm{P}$

$0.00<1.00 \quad$ NS

TI $x$ TS

$0.42 \quad 1.40 \quad$ NS

TI $x$ DOL

$0.14<1.00$ NS

TI $\times$ DOI $\times P$

$0.13<1.00 \quad$ NS

TI $x$ DOL $x$ TS

1.40

4.67

$\lessdot 05$

TI $\times$ SS/Groups

84

0.30 
Figure 2

Mean Number of Responses

Recalled in Ilst 1 MMFR Classified

for 2 Degrees of Original Learning

(OI=overlearning, $N=$ no overlearning)

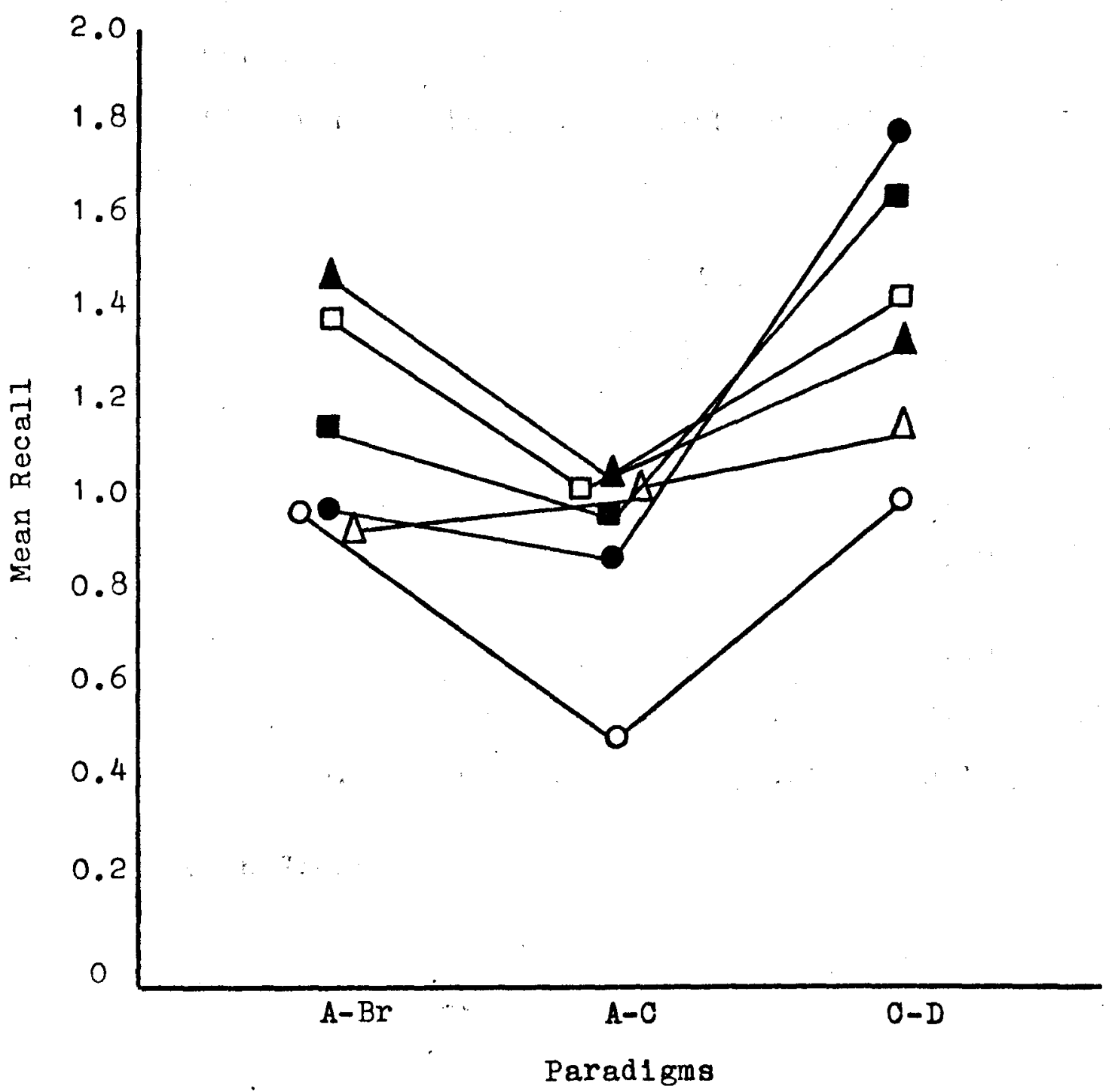
$\therefore$ Normal-OL
口 Normal-N
$\triangle$ Process-OL
- Reactive-OL
$\triangle$ Process-N
O Reactive-N 
Table 9

Means and Stanđard Deviations

for List 1 MMFR Difference Scores

Olassifled for 2 Degrees of Original Learning

(OI=overlearning, $N=$ no overlearning)

Group*

\begin{tabular}{lccccccc} 
& \multicolumn{2}{c}{ A-Br } & \multicolumn{2}{c}{ A-C } & \multicolumn{2}{c}{ C-D } \\
& Mean & S.D. & Mean & S.D. & Mean & S.D. \\
& & & & & & & \\
Process-OI & 0.20 & 0.54 & 0.00 & 0.00 & 0.27 & 0.45 \\
Reactive-OI & 0.20 & 0.54 & 0.13 & 0.22 & 0.40 & 0.61 \\
Normal-OI & 0.00 & 0.00 & 0.00 & 0.00 & 0.20 & 0.54 \\
Process-N & 0.40 & 0.61 & 0.13 & 0.33 & 0.20 & 0.40 \\
React1ve-N & 0.13 & 0.45 & 0.00 & 0.00 & 0.20 & 0.40 \\
Normal-N & 0.40 & 0.49 & 0.07 & 0.26 & 0.13 & 0.33
\end{tabular}

* $N=15$ in each Group

Parad 1gm
$A-C$ 
Table 10

Analysis of Varlance for

Ilst 1.MMFR Difference Scores

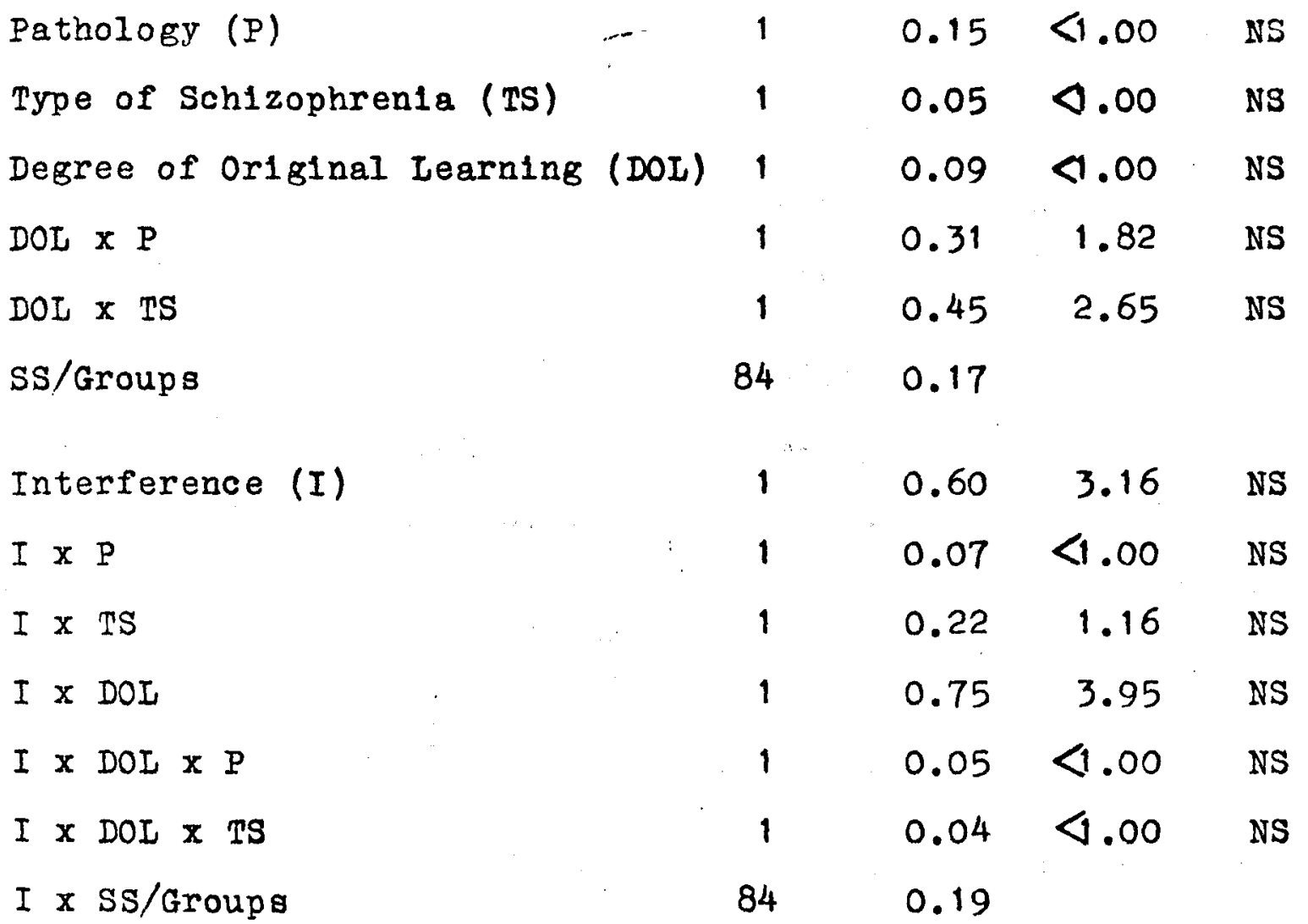

Type of Interference (TI)

II $\times P$

$1.42 \quad 17.75<01$

TI $x$ TS

$0.00 \varangle .00$ NS

TI $x$ DOL

$0.08 \quad 1.00 \quad$ NS

TI $\times$ DOL $\times P$

$0.21 \quad 2.62 \quad$ NS

TI $x$ DOI $x$ TS

$0.24 \quad 3.00 \quad$ NS

TI $x$ SS/Groups

$0.01<1.00$

NS

$84 \quad 0.08$

Total 
Table 11

Means and Standärd Deviations

for List 2 MMFR (Ienient scoring)

Classified for 2 Degrees of Original Learning

(OL=overlearning, $\mathrm{N}=$ no overlearning)

Group *

$$
\text { A-Br }
$$

Mean S.D.

$1.40 \quad 0.80$

1.60

1.40

1.73

$1.20 \quad 0.83$

$1.80 \quad 0.52$

1.530 .62
1.330 .60

1.130 .81

$\begin{array}{ll}1.33 & 0.79\end{array}$

Normal $-N$

*N=15 in each Group
0.61

0.88

0.46

Paradigm

$$
\text { A-C }
$$$$
C-D
$$

Mean S.D.

$1.80 \quad 0.40$

$1.67 \quad 0.58$

$2.00 \quad 0.00$

$1.87 \cdot 0.48$

$1.80 \quad 0.40$

$1.87 \quad 0.32$ 
Tab1 \& 12

Amalyals of Varlance of

Iist 2 NAYR (lenlant soor $(n x)$

Source

df

Mg

f

Pathology (P)

$1.562 .33 \quad$ NS

Type of Schizophrenia (TS)

1

$0.00 \quad 4.00 \quad$ NS

Degree of Original Learning (DOL)

DOL $\times \mathrm{P}$

1

DOL $x$ TS

1

$0.45<1.00$ NS

SS/Groups

84

$0.66 \ll .00$ NS

Interference (I)

1

$8.57 \quad 30.61<01$

0.67

1.00

NS

$I \times P$

0.67

$I \times$ TS

1

I $\mathbf{x}$ DOI

I $\times$ DOI $\times \mathrm{P}$

1

I $x$ DOL $x$ TS

1

I $\times$ SS/Groups

84

$0.00<.00 \quad$ NS

$0.18<1.00 \quad$ NS

$0.36 \quad 1.28 \quad$ NS

Type of Interference (TI)

1.42

$4.30<05$

TI $\times \mathbf{P}$

$0.04<1.00 \quad$ NS

TI $\times$ TS

$0.84 \quad 2.55 \quad$ NS

TI $x$ DOI

$0.23<.00$. NS

TI $\times$ DOL $\times \mathbf{P}$

$0.01<1.00 \quad$ NS

TI $x$ DOL $x$ TS

1.62

4.91

$<05$

II $x$ SS/Groups

84

0.33 
greater than in paradigm A-C whioh was in turn greater than in A-Br. A significant triple interaotion (type of 1nterference $x$ degree of orlglnal learning $x$ type of schizophrenia) was also present. With overlearning, process schlzophrenic Ss recalled a greater number of List 2 responses in the A-C paradigm than did reactives. There was little difference between the two groups in the A-Br paradigm. However, without overlearning, reactive SB recalled more L1st 2 response terms than did process Ss in the A-C paradigm. This difference was significantly greater than the difference between the groups in the A-Br paradigm. Analysis of List 2 MMFR difference scores (lenient scoring minus strict scoring) showed a main effect of type of interference $(\underline{p}<.01)$ and two significant triple interactions (a) type of interference $x$ degree of original learning $x$ pathology and, b) type of interference $x$ degree of original learning $x$ type of schizophrenia). The $p$ values were $\mathrm{p}<05$ for both interactions. The relevant data and analysis appear in Tables 13 and 14. Across groups, the $A-B r$ and $C-D$ paradigms were associated with signiflcantly greater losses in specific assoclations than was the $A-O$ paradigm. With overlearning, the schizophrenic Ss showed more loss of specific associations in the A-Br paradigm than did normal $\underline{S}$, and the difference between the two groups was signiflcantly greater than in the A-O paradigm. Conversely, without overlearning, the schizophrenic Ss showed more $10 \mathrm{~s}$ s of specific associations in the $\mathrm{A}-\mathrm{O}$ 


\begin{abstract}
Table 13
Means and Stañard Deviations

for Ilst 2 MMFR Difference Scores
\end{abstract}

Clasgifled for 2 Degrees of Original Learning

(OL=overlearning, $N=$ no overlearning)

Group*

$$
\mathrm{A}-\mathrm{Br}
$$

Parad 1 gm

A-C
$O-D$

Mean S.D. Mean S.D. Mean S.D.

Process-OL

0.070 .26

$0.00 \quad 0.00$

$0.07 \quad 0.26$

React1ve-OL

0.330 .47

0.13

0.35

$0.00 \quad 0.00$

Normal-OL

$0.00 \quad 0.00$

$0.00 \quad 0.00$

0.070 .26

Process-N

$0.20 \quad 0.40$

$0.07 \quad 0.26$

0.40

0.71

Reactive-N

0.070 .26

0.130 .33

0.13

$0.00 \quad 0.00$

0.13

0.40

0.00

*N=15 in each Group 
Table 14

Analysis of Varlanoe for

L1st 2 MMFR Difference Scorea

Source

df

MS *

$\mathbf{F}$

P

Pathology (P)

0.27

1.80

NS

Type of Schizophrenia (TS)

$0.00<1.00 \quad$ NS

Degree of Original Learning (DOL)

0.37

2.47

NS

DOL $\times$ P

$0.01 \ll .00$ NS

DOL $x$ TS.

0.56

3.73

NS

SS/Groups

84

0.15

Interference (I)

$0.07<1.00$

NS

I $\mathrm{X} P$

$0.01<1.00$ NS

I $\mathrm{X}$ TS

$0.62 \quad 2.82$ NS

I $x$ DOL

$0.36 \quad 1.64 \quad$ NS

I $\times$ DOI $\times \mathrm{P}$

0.26

1.18

NS

I $x$ DOL $x$ TS

0.00

$<.00$

NS

I $x$ SS/Groups

84

0.22

Type of Interference (TI)

0.36

7.20

$<01$

TI $x \quad P$

0.00

$<1.00$

NS

TI $x$ TS

$0.01<1.00 \quad$ NS

TI $x$ DOL

0.00

$<.00$

NS

TI $x$ DOL $x$ ?

0.24

4.80

$<05$

TI $x$ DOL $x$ TS

0.27

5.40

$<05$

TI $x$ SS/Groups

84

0.05 
paradigm than did normal Ss, and the difference between the two groups was signiflcantly greater than in the A-Br paradigm. Speolflcally, reactive schizophrenic Ss lost more specific associations in the A-Br paradigm than did process Ss, with overlearning, and the difference between the two groups was significantly greater than in the A-C paradigm. Without overlearning the converse held true. process Ss lost more specific associations in the A-Br paradigm than did reactive $\underline{S}$, and the difference between the two groups was significantly greater than in the A-C paradigm.

Intrusions

The above results suggested that an analysis of intrusion errors might provide additional information about differential group performances. Specific intrusions (IIst 1 responses appearing in Iist 2 to the appropriate stimuli) were analyzed for the A-C paradigm. Intrusions of this type were not analyzed in the A-Br paradigm, because they appeared to be approximately equal in both schizophrenic groups and because specific intrusions are completely confounded with intralist errors in this paradigm. The data and analysis appear in Tables 15 and 16, respectively. The main effects of pathology and of type of schizophrenia were found to be significant $(\mathrm{p}<01)$. The degree of original learning $x$ pathology interaction was also significant $(p<01)$. The analysis indicated that all groups were significantly different from each other when consldered across degrees of orlginal learning. 


\section{Table 15 \\ Means and Standard Deviations for Specific Intrusions in List 2 A-O Paradigm Learning} Classifled for 2 Degrees of Original Learning (OL=overlearning, N=no overlearning)

\begin{tabular}{lll}
\multicolumn{1}{c}{ Groups* } & Mean & S.D. \\
Process-OI & 0.54 & 0.71 \\
Reactive-OI & 0.34 & 0.82 \\
Normal-OI & 0.00 & 0.00 \\
Process-N & 0.34 & 0.69 \\
Reactive-N & 0.06 & 0.26 \\
Normal-N & 0.20 & 0.75 \\
\#N=15 in each Group & &
\end{tabular}




\section{Table 16 \\ Analysis of Variance \\ for Specific Intrusions in \\ List 2 A-C Paradigm Learning}

Source

$d f$

MS

p

$P$

Pathology (P)

1

0.94

13.43

$<01$

Type of Schizophrenia (TS)

1

0.8

11.57

$<01$

Degree of

or

Learning

(DOL)

1

0.18

2. 57

NS

DOI $\mathrm{X} P$

1

0.93

13.28

$<01$

DOI $x$ TS

1

0.0

$<.00$

NS

SS/Groups

84

0.07

Total

89 
Process schlzophrentc Is made more opeo1flo intmision errors than did reactive $\underline{S}$, who in turn made more errors than normal Ss. Also, schizophrenic Ss made more intrusion errors in the overlearning condition than did normal Ss, and this difference was signifloantly greater than 1 t was in the no overlearning condition. 


\section{Discussion}

The main methodological results of this study will be discussed first. The interactions with pathology will be more clear once this has been done. The results of this study affirm the efflcacy of the verbal learning methodology used to manipulate associative interference. of 12 main effects attributable to paradigmatic variation, 10 yielded results significant beyond the .05 level; most were significant far beyond .001. One of the two remalning effects was significant at the .10 level, and both of these results were found in MMFR difference score analyses (lentent scoring minus strict scoring). Furthermore, most of these results were in accord with expectations based on both prior findings and theory. Those that were not expected provide insight into the mechanisms of interference in the various paradigms and, for the most part, are compatible with recent findings of verbal learning researchers.

The analysis of Iist 2 errors (Tables 5 and 6) provided paradigmatic findings in accord with expectation. The A-Br paradigm showed more interference than A-O which in turn showed greater interference than the no interference control paradigm (O-D). These results paralleled the findings with normal populations (e.g., college students). 
The findings in Iist 1 MMFR under lenlent sooring (Tables 7 and 8) were concordant with expectation based on retroactive inhibition of Iist 1 response terms in the A-O paradigm. Greater $\mathrm{A}-\mathrm{Br}$ than $\mathrm{A}-\mathrm{C}$ recall was expected $\mathrm{B}$ iven that the same response terms were required in both List 1 and List 2 for this paradigm. That is, as appropriate List 1 responses were being 1nhibited during list 2 learning the same responses were beling reinforced w1th respect to different stimuli. The probability of recall of the response, then, remalned relatively high. of course, C-D, as expected, showed the best response recall, because no experimental associative interference was present in this paradigm.

Iist 1 MMFR analysis for loss of specific associations (Tables 9 and 10) ylelded evidence (1.e., significant main effect of type of interference) which provided some support for the immunity of the A-O paradigm to disruption due to loss of specific associations (Postman and Stark, 1969). However, appearance of these losses at an equal level in the O-D paradigm suggested that the1r relative absence in A-C was contingent upon fallure of recall in this paradigm. Thus, analysis under lenient and strict scoring would be redundant in this respect. Yet, the occurance of loss of specific associations was higher in the $C-D$ paradigm for this study than in that of Postman and Stark. No difference between lenlent and stringent scoring was found for C-D in that study. The present 
study employed a mixed list technique whereas Postman and Stark did not; the mixed list technique might have allowed generalization of dismption of speciflo associations across paradigms.

The results of Ilst 2 MMFR under lenlent scoring criteria (Tables 11 and 12) were somewhat surprising. The C-D paradigm was expected to show best recall followed in order by $A-B r$ and $A-C$. However, supertority of $A-O$ recall to A-Br recall was found. Many Investigators have pald little attention to second list retention, but those who have (e.g., Postman, 1962a) reported uniform recall across paradigms with college student Ss.

The present findings were seen as being compatible with those of Postman and Stark (1969). It seemed likely that the dismption of specific associations in the $\mathrm{A}-\mathrm{Br}$ paradigm contributed to the loss of response terms during second list learning at a rate greater than that attributable to retroactive inhibition alone. These losses appeared in List 2 recall, where, wi thout such losses, high response avallability would have been expected. List 2 difference. scores (Tables 13 and 14) provided additional support. Equally high losses of specific associations appeared in paradigms $A-B r$ and $C-D$ w1 th little loss in A-C. These findings parallel the paradigmatic differences noted earlier in L1st. 1 MMFR. However, unlike the situation for L1st 1, where no distinction between loss of specific assoclations and low response avallability could be made, here 
one of the high recall paradigms under lenlent scoring (A-O) showed low dismption of spe01f10 aseoolations. Thus, loss of speciflc associations was not necessarily dependent on response avallability. That this should be true for the other paradigms seemed reasonable. In this light, MMFR for both 11 sts reflected the relative immunity of the A-C paradigm to disruption of specific associations, the expected disruption in paradigm $A-B r$, and the highly unexpected susceptibility of $O-D$ to such disruption in a mixed 11 st.

The other major verbal learning methodological technique (1.e., the use of two degrees of original learning) employed in this study did not produce any significant main effects. The expected interaction with the A-Br paradigm to create especially high associative interference (IIst 2 errors) was not found. Al though there was no indication from the present data concerning the reason for this negative result, the relatively short list length (six pairs) seemed to provide a likely answer (James and Greeno, 1970). However, the degree of original learning was found to interact significantly with pathology in the analysis of specific Iist 1 intrusions in List 2 A-O learning (Tables 15 and 16). Complex interactions between this factor and those of type of interference and type of schizophrenia in the MMFR data were also found.

The major findings of this study can now be understood in Iight of the particular methodology used. The main effect of pathology found in the analysis of I1st 2 errors 
(rables 5 and 6) resulted, at least in part, from the sens1llvity of the schizophrenic $\underline{s}$ s to the interference created In the experimental paradigms. Two factors indicated that the greater number of schizophrenic errors did not.result from generally impalred learning ability, attentional deficlt, or flagging motivation. First the groups were matched or Initial learning ability as Indicated by List 1 acquisitIon rate (1.e., number of trials to criterion). Second, there were no signiflcant differences between groups in the $S-D$ control paradigm. In general, the results of Kausler et al. were confirmed. The performance of schizophrenic Individuals was more disrupted by associative interference than was the performance of normal individuals. Further, the use of experimental procedures to manipulate interferance in comparison to extra-experimental or normative technlques (as done in most assoclative interference in schizoshrenia studies) was supported.

The finding of a slgnificant type of interference $x$ type of schizophrenia interaction in the L1st 2 error data vas directly related to the hypothesis upon which this study was based. From figure 1, it was clear that the percornance of reactive or good premorbid schizophrenic Ss, ville 1mpaired, paralleled the performance of normal Ss w1th respect to the relationship between errors in the $\mathrm{A}-\mathrm{Br}$ and A-O Daradigms. However, the performance of process or poor venorbid Ss differed from that of the other two groups; it Ild not improve in paradigm A-C as would have been expected. 
Given the nature of the A-O paradigm, the most tenable explanation of this finding appeared to be that prooese schizophrenic Ss failed to inhibit or extinguish first list response terms to a greater extent than did the oother two groups. List 1 MMFR (lenient scoring) provided some supporting evidence (Tables 7 and 8 ). The triple interaction (type of Interferenoe $x$ deproo of orleinal Inarnine $x$ tivie

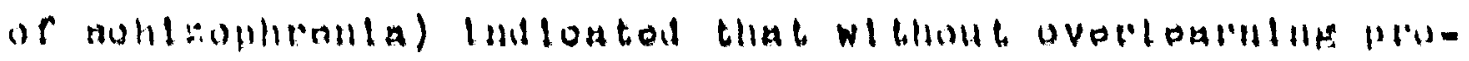
cess Sg recalled Llat 1 responge terms in the A-O paradigm much better than did reactive Ss. In fact poor premorbid Ss recalled A-C responses as well as A-Br responses under these conditions. This was not true of good premorbid schlzophrentc Ss or normal Ss. Both of these groups tended to show a response recall decrement in the A-C paradigm relative to $\mathrm{A}-\mathrm{Br}$. However, overlearning on List 1 appeared to eradicate the recall decrement in A-O for reactive Ss and normal Ss. It also slightly increased process schizophrenic recall in paradigm A-Br. Simply, process schizo-

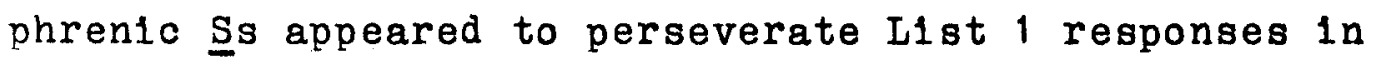
paradigms $A-C$ and $A-B r$. Overlearning appeared to Increase this perseveration in the $A-B r$ paradigm relative to reactive Ss and appeared to make the inhlbition of first list response terms in paradigm A-C more difficult for reactive schlzophrenic and normal S.

Strong support for this interpretation was found in paradigm specific intrusions in $A-C$ during Ist 2 learning (Tables 15 and 16). Significant differences were found 
between all S groups. Poor premorb1d echizophrenic ss made more intrusion errors than did good premorbid ss. Reactive

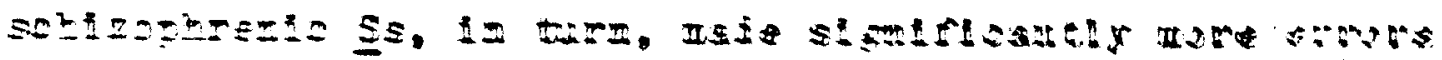
than did normal Ss. Again, schizophrenic Ss perseverated List 1 response terms, and it was the process $\underline{\text { S }}$ ' performance on Iist 2 that was most disrupted by this failure of response inhibition. A significant interaction of degree of orlginal learning and pathology was also found. Schizophrenic Ss perseverated more with overlearning than without, and this difference was signiflcantly greater than the tendency for normal $\underline{S}$ s to make more intrusion errors without overlearning. Thus, overlearning made the inhibition of

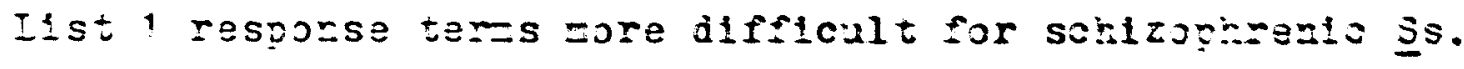
This finding was congruent with the results of Iist 1 MMFR. Returning to a consideration of list 2 errors, good evidence seemed to exist supporting the conception that process schlzophrenic Ss falled to inhibit LIat 1 response terms in the first stage of A-O learning on the second 11st. That the same mechanism should account for the process schizophrenic deficit seen in the A-Br paradigm seemed reasonable. Unfortunately direct evidence, such as the Intrusions into Iist 2 learning analyzed for A-C, was not avallable in this paradigm. However, should this supposition have been correct, then the equally poor performance of both schizophrenic groups in paradigm A-Br would have resulted from different types of deficit. Reactive schizophrenic Ss were disrupted by response competition and 1 ts 
consequent associative Interference (Goulet, 1968; Underwood, Runquist, and Schulz, 1959) and by the Interference with specific associations characteristic of paradigm $A-B r$ (Postman and Stark, 1969). General evidence from the present study concerning the nature of A-Br interference was cited earlier.

Further evidence in support of this conception was found in the analysis of List 2 MMFR difference scores (lenlent scorlng minus strict scorlng). The data and analysis appear in Tables 13 and 14.

A significant type of interference $x$ degree of or1ginal learning $x$ pathology interaction was found. Schizophrenic SS showed more loss of specific associations in paradigm A-Br than did normal Ss with overlearning, and this difference was signiflcantly greater than that found between the groups in A-C. Without overlearning, schizophrenic SS st1ll showed slightly greater loss of specific assoclations in paradigm $\mathrm{A}-\mathrm{Br}$ than did normal $\underline{S}$, but in this case the difference between the two groups was signiflcantly greater in paradigm A-O. The triple interaction Involving the schizophrenic groups further emphasized differences in the A-Br paradigm although these differences only partially supported the hypothesis put forth (1.e., that loss of specific associations would be greatest for reactive $\underline{S}$ in the $A-B r$ paradi $g m$ ). With overlearning, reactive schlzophrenic $\underline{S}$ s showed more loss of spectflc assoclations in the A-Br paradigm than did process Ss, and this 
differenoe was signiflcantly greater than that found in the A-C paradigm. However, without overlearning poor premorbid Ss showed more loss of specific associations in $\mathrm{A}-\mathrm{Br}$ than did good premorbid $\underline{S}$, and this difference was significantly greater than the difference between the two groups in paradi gm A-C.

In summary, the data from the present study provided firm evidence that process schizophrenic $\underline{S}$ perseverate old verbal $S-R$ relationships into new learning where success specifically requires the inhibition of these very relation-

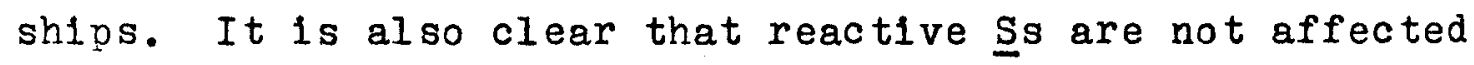
in the same manner to as great an extent. A reasonable explanation of the equal deficit of these groups in the learning of a new verbal task requiring the recombination of old stimuli and responses appears to be that process $\underline{S} s$ perseverate the old combination of stimulus and response, while reactive $\underline{S} s$ are dismpted by the more usual assoc1at1ve interference resulting from response competition and loss of specific associations connected with negative transfer in this type of task.

The hypothesis upon which this study was based appears to have been supported. React1ve schlzophrentc $\underline{\text { s s showed }}$ greater performance deficit with increasing associative Interference in a task than did process schizophrenlc Ss and normal Ss: However, the hypothesis did not anticipate finding the process $\underline{S}$ performance deficit based on response perseveration. 
The results of this study are not completely conoordant with the results of the only comparable study in the l1terature (1.e., Kausler et al., 1964). In terms of absolute transfer that investigation found a significant difference between schizophrenic Ss and normal Ss only in the A-Br paradigm. The use of chronic schizophrenic Ss makes this result all the more confusing. Length of hospitalization for these $\underline{S} s$ and the criteria for chronicity are unknown. Kausler et al. did note that the $\underline{S}$ were in partial remission. The Ss in the present study, by contrast, were acute (maximum current hospltalization of one year). The overwhelming majority of these ss participated in the experiment within three weeks of admission. Thus, many Ss, and partlcularly process Ss, were still quite disturbed at the time that they were seen. It may be that the process $\underline{S} s$ in the current study were manifesting the cognitive style most typical of acutely disturbed process (chronic) schizophrenia, while the Kausler et al. Ss may have returned in part to a cognitive structure characteristic of a less disrupted state (Weiner, 1966).

The present research was stimulated in part by Mednick's (1958) high-drive theory of sohizophrenia. What are the implications of this study's findings for that theory? If the good-poor premorbid concept is subst1 tuted for the acute-chronic distinction of Mednick, the results can be seen as supporting the Mednicklan hypothesis. Mednick predicted schlzophrenlc performance decrement with 
Increasing task complexity on the assumption that high drive would interfere with response integration and production in such tasks. Although he was not clear about it, this hypothesis would seem to hold more for acute than chronic schizophrenics, because of the drive reduction found in chronic schizophrenics brought about by tangential, drive reducing thoughts. However, Mednlck (1958) did note that:

...even the chronic patient is in one sense a very anxious person. He has never had the opportunity to extinguish his prepsychotic fears. They are still elicitable; all that is required is that one break through the schizophrenic's "associative curtains (p. 324$)$."

The reactive schizophrenics in this study showed Increasing performance decrement as task complexity increased from A-C to the A-Br paradigm. Th1s was the result of increasing associative interference consequent to response competition, and in $A-B r$ to disruption of specific associations. The process schizophrenics, on the other hand, reacted to increasing task complexity in a manner in keeping with a lower drive state, 1.e., they simply perseverated old learning. Both of these findings appear to be supportive of Mednick's conception.

DeWolfe (1971) has elaborated a theory of sch1zophrenic cognitive deficit based on modified Hullian drive notions. His concepualization is similar in some respects to Mednick's, theory. He explained the schizophrenics' motivational state in terms of avallable coping energy (ACE). Th1s is energy avallable to the 1ndividual for adaptive functioning and not so undirected with respect to 
stimulus as to be disruptive, nor so invested in defense as to be unavallable. DeWolfe hypothesized an Inverted-U relationship between $A C E$ and emotional expression. He further refined his theory by noting that the differing premorbid Iffe experiences of process and reactive schizophrenics lead to different cognitive structures in the two groups. He related $\mathrm{ACE}$ and cognitive stmacture to task performance. The results of the current study are compatible with Dewolfe's theory. Process schizophrenics were described by Dewolfe as performing poorly at all levels of external stress because of their history of reduced consensual perception and cognitive function and low energy avallable for task relevant behavior. However, increased external stimulation may improve their performance somewhat in that the arousal increment may increase their level of ACE. In the present study, the process Ss performed adequately in the C-D paradigm (a simple task). However, their performance showed a decrement in paradigms $A-C$ and $A-B r$ where the presence of associative interference called for a high level of ACE to adequately meet the task. In these paradigms ACE may have actually been reduced for process Ss by withdrawal of affect. The remaining ACE may have been channeled into the least energy demanding behavior, 1.e., perseveration of List 1 responses. In fact, it is posslble that process $\underline{S}$ selectively withdrew $\mathrm{ACE}$ investment in $\mathrm{A}-\mathrm{Br}$ and $\mathrm{A}-\mathrm{C}$ and used it in the C-D paradigm (the easiest task) to produce an adequate performance. 
DeWolfe predicted different oognltive deficits under low and high strese for good premorbid cohleophrenlog. He expected that under low stress and wth simple tasks react1ve schlzophrentes would show performance superior to process schizophrenics and similar to that of normals. This prediction was based on the relatively normal cognitive development and social functioning of these individuals during the premorbid period. With low external stress less emotional expression was expected with a concommitant increase in $A C E$. In the A-O paradigm with intermediate assoclative interference and possibly intermediate arousal, react1ve Ss showed negative transfer, but their performance was more similar to the normal Ss than to that of process Ss. However, in paradigm A-Br reactive $\underline{\text { Ss }}$ were disabled much more than normal $\underline{S}$ s and were similar to process $\underline{S}$. DeWolfe's theory would predict this good premorbid performance deficit because of extreme emotional reactivity under high external stress (1.e., the great interference in the task) which would reduce AOE. Thus, DeWolfe's theory with its emphasis on a drive-stimulus $\left(S_{D}\right)$ formulation rather than on a generalized drive (D) conceptualization accounts well for the current results.
A fairly simple explanation of the results of this study may be found Implicitly in Mednick's conceptualization and in the theorizing of DeWolfe. The Increasing disruption of reactive schizophrenics with increasing task complexity is the result of the interaction of high drive and associa- 
tive interference. Prooess sohizophrenios have learned to reduce drive by thinking tangential thoughts (Mednlok) and by social and emotional withdrawal (DeWolfe). The present study indicates that process schizophrenics may protect (defend) against drive increases by repeating the task relevant behaviors of least drive-evoking nature, 1.e., in the face of associative interference they perseverate old, simple, less drive elevating Ilst 1 stimulus-response relationsh1ps. Reactive schizophrenics, on the other hand, have not learned this defensive response because their premorbid life experience has not required 1t. Therefore they are subject not only to performance disruption but probably to some reciprocal augmentation of drive.

One final, possible explanation of the findings should be mentioned. Although the use of the term "perseveration" to describe the behavior of process schizophrenics in this study need not 1mply the existence of intra-cranial organic pathology in this group, this is an explanation which some would put forth (e.g., Belmont, Blrch, Kleln, and Pollack, 1964). Reactive schizophrenics in this context might be disrupted by the interaction of their drive atate (psychogenic) and task complexity. The process Ss, however, respond to task complexity by perseverative behavior which belies their underlying neurological damage. While several explanations of the current findings are possible, those incorporating aspects of drive theory seem most acceptable. Mednlck's theory appears to be most 
parsimonious not requiring the additional concept of $10 E$ needed by DeWolfe's formulation. However, some existing process-reactive 11 terature in other areas appears to be best explained by the use of this concept. Further empirical test should help to ascertain whether or not ACE is a necessary concept. The results of the present study hopefully will serve as impetus to reopen investigation in the area of associative processes and interference in schizophrenia. Not only will such research possibly contribute to an answer for the theoretical question ralsed above, but may also lead to Investigations concerning differential therapeutic interventions in schizophrenia. The difference found in the nature of the verbal learning deficit in good and poor premorbid schizophrenics points to the need for such a discrimination. 


\section{Summary}

A mixed list (paradigmo $A-B r, A-0$, and $C-D$ ) verbal learning technique was used to study the effects of increasing associative interference in tasks upon the performance of process and reactive schizophrenic and normal Ss. The experimental manipulation of interference was found to be effective and produced negative transfer in $A-B r$ and $A-C$ for all Ss. The schizophrenic $\underline{S}$, as a group, showed significantly greater performance decrement in paradigms causing associative interference than did normal Ss. Process Ss were equally disrupted in paradigms $\mathrm{A}-\mathrm{Br}$ and $\mathrm{A}-\mathrm{C}$. Reactive S.s were disrupted to an extent equal to that of process $\underline{S}$ in $\mathrm{A}-\mathrm{Br}$ but showed less performance decrement in $\mathrm{A}-\mathrm{C}$. Analysis of paradigm specific List 1 response intrusions Into List 2 learning in A-C showed process Ss perseverating L1st 1 responses to a slgnificantly greater extent than react1ve $\underline{\text { Ss }}$ who in turn perseverated such responses more than normal Ss. The findings were seen as reflecting react1ve schizophrenic performance disruption under conditions of negative transfer as resulting from assoclative interference based on response competition and the $108 \mathrm{~s}$ of specific associations. Process Ss were seen as responding to the same interference factors by perseveration of old learning. The implications for several theories of schizophrenic etiology, including Mednick's high-drive theory, were discussed. 


\section{Append1 $x$}

Experimental Lists

IIst 1 pairs

KIng-Music

Eagle-Rough

Baby-Iong

Table-Fruit

Justice-Quiet

Dream-Green
Ilst 2 pairs

K1ng-Rough

Eagle-Music

Baby-Anger

Table-Heal th

Priest-Window

City-SIow 


\section{References}

Barnes, J. M., and Underwood, B. J. "Fate" of f1rst-11st associations in transfer-theory. Journal of Experimental Psychology, 1959, 58, 97-105.

Belmont, I., Blrch, H. G., Kleln, D. F., and Pollack, M. Perceptual evidence of CNS dysfunction in schizophrenia. Archives of General Psychiatry, 1964, 10, 395-407. Bleuler, E. Dementia praecox or the group of schizophrenias. New York: International University Press, 1950 .

Briggs, G. E. Acquisition, extinction, and recovery functions in retroactive inhibition. Journal of Experimental Psychology, 1954, 47, 285-293. Broen, W. E., and Storms, L. H. Lawful disorganization: The process underlying a schizophrenic syndrome. Psychological Review, 1966, 73, 265-279.

Carson, R. C. Intra-list similarity and verbal rote learning performance of schizophrenic and cortically damaged patients. Journal of Abnormal and Soc1al Psychology, 1958, 57, 99-106. Crider, A. B., Grinspoon, I., and Maher, B. A. Autonomic and psychomotor correlates of premorbld adjustment in schizophrenia. Psychosomat1c Medicine, 1965, 27, $201-206$ 
Delprato, D. J., and Garskof, B. E. Unlearning in the absence of now learning. Journal of Verbal Learning and Verbal Behavior, 1969, $8,388-392$.

DeWolfe, A. S. Self-reports and case histories of schizophrenic patients: Reliability and validity of Phillips scale ratings. Journal of Clinical Psychology, 1963, 24, $415-418$.

DeWolfe, A. S. Premorbid adjustment, conceptual functioning, and avallable coping energy in schizophrenia. Unpublished paper, 1971.

Donahoe, J. W., Curtin, M. E., and Lipton, I. Interference effects with schizophrenic subjects in the acquisition and retention of verbal material. Journal of Abnormal and Social Psychology, 1961, 62, 553-558.

Donoghue, J. R. Motivation and conceptualization in process and reactive schizophrenla. Doctoral dissertation, University of Nebraska, No. 64-8875. University Microfilms, Ann Arbor, Michigan, 1964. Epstein, S., and Coleman, M. Drive theories of schizophrenia. Psychosomatic Medic1ne, 1970, 32, 113-140. Fowles, D. O., Watt, N. F., Maher, B. A., and Grinspoon, I. Autonomic arousal in good and poor premorbid schizophrenics. British Journal of Soc1al and Clinical Psychology, 1970, 9, 133-147. 
Glad1s, M., and W1schner, G. J. Soh1zophrenic and normal response patterns to "aversive" and "noutral" associations in two paired-associate paradigms. Journal of Abnormal and Soclal Psychology, 1962, 64, 249-256. Gonen, J. Y. Associative interference in schizophrenia as a function of paranoid status and premorbid adjustment. Journal of Consulting and Clinical Psychology, 1970, 34, $221-225$.

Goldet, L. R. Anxiety (drive) in verbal learning: Implications for research and some methodological considerations. Psychological Bulletin, 1968, 69, 235-247. Herron, W. G. The process-reactive classification of schizophrenia. Psychological Bulletin, 1962, 59, 329-343. Higgins, J. The concept of process-reactive schizophrenla: Criteria and related research. Journal of Nervous and Mental Disease, 1964, 138, 9-25. H1ggins, J. Process-reactive schizophrenia. Journal of Nervous and Mental Disease, 1969, 149, 450-472. Higgins, J., Mednick, S. A., Philip, F. J., and Thompson, R. E. Assoclative responses to evaluative and sexual verbal stimull by process and reactive schizophrenics. Journal of Nervous and Mental D1sease, 1966, 142, 223227.

H1ggins, J., Mednick, S. A., and Thompson, R. E. Acqu1s1tion and retention of remote associates in processreactive schizophrenia. Journal of Nervous and Mental Disease, $1966,142,418-423$. 
Higgins, J., and Peterson, J. O. Conoept of process-

reactive schizophrenla: A critique. Pgychological Bullet1n, 1966, 66, 201-206.

Hull, C. I. Princlples of behavior. New York:- Appleton, 1943.

Irwin, L., and Renner, E. K: Effect of praise and censure on schizophrenics. Journal of Abnormal Psychology, 1969, 74, 221-226.

James, C. T., and Greeno, J. G. Effect of A-B overtraining In A-Br. Journal of Experimental Psychology, 1970, 83, $107-111$.

Jongsma, A., Sullivan, D., and Martin, R. B. Adjustment and chronicity in simple and complex learning of schizophrenics and normals. Journal of Clinical Psychology, 1969, 25, 152-155.

Jung, J. Transfer of training as a function of degree of first-list learning. Journal of Verbal Learning and Verbal Behavior, 1962, 1, 197-199.

Kapche, R. Associative response competition in schizophrenia. Journal of Abnormal Psychology, 1969, 74, $75-78$.

Kausler, D. H., and Kanot1, G. A. R-S learning and negative transfer effects with a mixed 11st. Journal of Experimental Psychology, 1963, 65, 201-205. 
Kausler, D. H., IaIr, O. V., and Matsumoto, R. Interference trangfer paradigms and the performance of schizophrenics and controls. Journal of Abnormal and Social Psychology, 1964, 69, 584-587.

Klein, E. B., Clcchett1, D., and Spohn, H. A test of the censure-deficit model and its relation to premorbidity In the performance of schizophrentes. Journal of Abnormal Psychology, 1967, 72, 174-181.

Mandler, G. From association to structure. Psychological Review, 1962, 69, 415-427.

Mednick, S. A. A learning theory approach to research in schizophrenia. Psychological Bulletin, 1958, 55, $316-327$.

Melton, A. W. Comments on Professor Postman's paper. In C. N. Cofer (Ed.), Verbal learning and verbal behavior. New York: McGraw-H11I, 1961.

Phillips, E. Case history data and prognosis in schizophrenia. Journal of Nervous and Mental Disease, 1953, 117, 515-525.

Postman, I. Transfer of training as a function of experimental paradigm and degree of first-11at learning. Journal of Verbal Learning and Verbal Behavior, 1962, 1. 109-110. (a)

Postman, I. Retention of first-list associations as a function of the conditions of transfer. Journal of Experimental Psychology, 1962, 64, 380-387. 
Postman, I., and Stark, K. Role of response avallab1lity

In transfer and Interference. Journal of Experimental Psychology, 1969, 79, 168-177.

Relsman, J. M. Motivational differences between.process and reactive schizophrenics. Journal of Personality, $1960,28,12-25$.

Reynolds, R. D. Operant response as a function of premorbid adjustment of schizophrenic subjects. Dissertation Abstracts, 1965, 26, 1173-1174.

Russell, W. A., and Jenkins, J. J. The complete Minnesota norms for responses to 100 words from the Kent-Rosanoff Word Association Test. Technical Report Number 11 , Contract N6 ONR-66216 (1954).

Schooler, C., and Tecce, J. J. Verbal palred-associates learning in chronic schizophrenics as a function of positive and negative evaluation. Journal of Abnormal Psychology, 1967, 72, 151-156.

Schweid, E. I. Verbal reaction times of schizophrenics under varying conditions of noxious stimulation. Doctoral dissertation, University of Washington, No. 6612,045. Un1versity Microfilms, Ann Arbor, Michigan, 1966.

Slamecka, N. J. Transfer with mixed and unmixed 11 sts as a function of semantic relations. Journal of Experimental Psychology, 1967, 73, 405-410. 
Smith, W. O. Rotary purgult performanoe in reaotive and process sch1zophrenics, Dissertation Abstracts, 1961, 21, $2787-2788$.

Solso, R. L. Effects of meaningfulness and massive first list practice on transfer. Paper presented at the Midwestern Psychological Association, Chicago, May, 1969.

Spence, J. T., and Lair, O. V. Associative interference in the verbal learning performance of schizophrenics and normals. Journal of Abnormal and Social Psychology, $1964,68,204-209$.

Storms, L. H., and Broen, W. E. A theory of schlzophrenic behavioral disorganization. Archives of General Psychiatry, 1969, 20, 129-144.

Strelner, D. I. Effects of task complexity and verbal evaluation on the learning of normals and schizophrenics. Journal of Abnormal Psychology, 1969, 74, $606-611$.

Thorndike, E. L., and Lorge, I. The teacher's word book of 30,000 words. New York: Bureau of Publications, Teachers College, 1944.

Twedt, H. M., and Underwood, B. J. Mixed vs, unmixed lists in transfer studies. Journal of Experimental Psychology, 1959, 58, 111-116. 
Underwood, B. J., Runquist, W. N., and Sohulz, R. W.

Response learning in palred-associates 11sts as a function of intralist similarity. Journal of Experimental Psychology, 1959, 58, 70-78.

Underwood, B. J., and Schulz, R. W. Meanlngfulness and verbal learning. Philadelphia: Lippincott, 1960. We1ner, I. B. Psychodiagnosis in schizophrenia. New York: W11ey, 1966.

Zlotowsk1, M., and Bakan, P. Behavioral varlab1l1ty of process and reactive schizophrenics in a binary guessing task. Journal of Abnormal and Soc1al Psychology, 1963, 66, 185-187. 


\section{APPROVAL SHEET}

The Dissertation submitted by Clifford L. Hirsch has been read and approved by members of the Department of Psychology.

The final copies have been examined by the director of the Dissertation and the signature which appears below verifies the fact that any necessary changes have been incorporated and that the Dissertation is now given final approval with reference to content and form.

The Dissertation is therefore accepted in partial fulfillment of the requirements for the degree of Doctor of Philosophy.
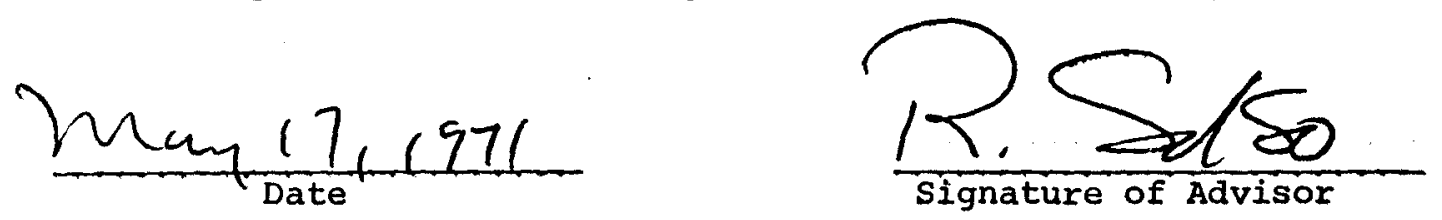